\title{
MODERNISM AND THE NARRATIVE OF NATION IN JFK ${ }^{1}$
}

Robert Burgoyne

The debate over Oliver Stone's JFK has been framed to date largely within the discourse of historiography, with greatest attention being paid to issues concerning the limits of fact and fiction, and the erosion of the presumed boundary between documentary and imaginative reconstruction. ${ }^{2}$ Defenders of the film have usually argued from a deeply theoretical position, pointing out the permeable nature of the border between factual discourse and imaginative reconstruction, as well as the protean quality of even the most substantial documentary record of the past. ${ }^{3}$ In this essay, I wish to shift the angle of approach to the film in order to consider another set of questions, revolving chiefly around the tension between the film's formal innovations and its explicit aim to articulate a narrative of national cohesion. The film's fragmentary form, I argue, can be revealingly seen as an expression of a national narrative in disorder and disarray, its collage-like narrative structure reflecting the disruption of the evolutionary or historical narrative that gives continuity to national identity. From this perspective, the film's notorious mixing of idioms conveys meanings that depart from issues of fact and fiction: rather, it expresses the fracturing of historical identity, the breaking apart of a once unified national text. The film thus recuperates its radically discontinuous style, I argue, by linking it to the loss of what Benedict Anderson called social "unisonance," to the absence of a unified national narrative which it nostalgically evokes as 


\section{Robert Burgoyne}

the foundation of community and the ground for all other narratives of human connection. ${ }^{4}$.

The concept of nationalism has increasingly been tied to the development of particular narrative forms. ${ }^{5}$ In writing of the nation as an "imagined community," for example, Anderson has linked the ideology of the modern nation to a specific sense of space and time expressed most clearly in the narrative forms of the realist novel. The temporal parallelism of the realist novel-the sense of temporal coincidence and simultaneity, of a multitude of unrelated actions occurring in a single community in what Walter Benjamin calls "homogeneous, empty time" - is directly related, in Anderson's view, to the image of the modern nation: "The idea of a sociological organism moving calendrically through homogeneous, empty time is a precise analogue of the idea of the nation, which is also conceived as a solid community moving steadily down (or up) in history. ${ }^{16}$ Emerging as a strong form in tandem with the rise of nations, the realist novel, with its composite structure, its depiction of the one yet many of national life, and its temporal parallelism "allowed people to imagine the special community that is the nation." ${ }^{\prime \prime}$ As Anderson says, the structure of the realist novel as well as the newspaper, both of which are crucial to the development of the "imagined community," can be seen as forming a "complex gloss upon the word 'meanwhile."'"

By contrast, Hayden White has argued in a recent essay that modernist anti-narrative techniques, characterized by fragmentation, the exploding of the conventions of the traditional tale, and the dissociation or splitting of narrative functions, may be the most appropriate techniques for representing the historical reality of the contemporary period, with its unprecedented catastrophes and its compound global contexts. ${ }^{9}$ His hypothesis-that there is a deep connection between the cultural genres of modernist aesthetic practice and the social dramas of the twentieth century-provides a suggestive contrast with Anderson's ideas about the cultural models of the nationbuilding past. White argues that the stylistic techniques of modernism, 
far from being ahistorical, or removed from history as so many critics have contended, provide better instruments for representing the recent events of the past than do the storytelling conventions of traditional historians, or, for that matter, the storytelling conventions of realism. Traditional forms of historical explanation, relying on concepts of human agency and causality, assume a kind of narrative omniscience over events which, by their scale and magnitude, elude a totalizing explanation. Modernist forms, in contrast, offer the possibility of representing, for the Western world, the traumatic events of the twentieth century, such as the two World Wars, the Great Depression, and the use of genocide as a state policy, in a manner that does not pretend to contain or define them.

In these pages, I address the film JFK in terms of both of these models, hoping to show how JFK utilizes modernist, anti-narrative techniques in order to express both the loss and the refiguration of a unified national identity. I argue that while the broken narratives and the profusion of stylistic forms in the film may seem at first appropriate to the catastrophic event of a presidential assassination and, indeed, convey a sense of a fractured social reality, they are ultimately recontained in a nostalgic image of social unisonance in the film's closing scenes.

\section{The temporality of trauma}

The disjointed temporality and dislocated spaces of JFK can be read as reflecting the distorted and irrational sense of national identity, and the fragmented social reality that the film finds at the heart of the United States in the post-Kennedy era. Far from seeing the nation as a "solid community moving steadily down (or up) in history," the spatial, temporal and narrative strategies of the film evoke division, rupture, and discontinuity between communities, individuals and their actions, and between events and their causes. Analysis of the temporal register

of the film in light of the idea of the nation as "imagined community" is 


\section{Robert Burgoyne}

especially revealing. The complex system of narrative temporality in $J F K$, to start with, is very far from the image of "homogeneous, empty time" filled up by the "steady, anonymous, simultaneous activity" conjured by the realist novel. Instead, the most striking characteristic of the film is its interweaving of past and present through an extraordinary combination of flashbacks, flashforwards, and achronic imagesimages that cannot be dated or assigned a temporal position. Moreover, time constitutes one of the principal thematic motifs in the film. Far from being seen as empty and homogeneous, time is thematized as heterogeneous and subject to human manipulation. Examples include the extensive newspaper report on Oswald that appeared in a New Zealand paper four hours before he was charged with Kennedy's murder; the Life magazine photo of Oswald with its contradictory times of day; the impossible chronology of Oswald's day on the date of the assassination; the delay in bringing Oswald down into the lobby of the jail, which allowed Jack Ruby to take his place among the crowd; the phone lines into Washington that went out for hours immediately after the assassination; the live oak in Dealey Plaza that the Warren Commission claimed had unnaturally dropped its leaves in November, affording Oswald an unobstructed view; the shots themselves, with the Zapruder film serving as the "clock" of the assassination, giving the lie to the "magic bullet" theory which would have us believe that a bullet could suspend itself in mid-flight for one and a half seconds. The overall picture of time that emerges is not one of uniform consistency, but of simultaneity corrupted by inexplicable delays, gaps, compressions, accelerations, and contradictions. Rather than fostering a sense of the security of parallel lives moving along the same trajectory, the film evokes time as a dimension that can be manipulated, a dimension that is open to doubt, to ambiguity, and to suspicion.

A comparison of two scenes in the film illustrates the close connection the text makes between structures of temporality and concepts of the national narrative and national identity. At the beginning of the film, time and date are specified exactly through voice over, 
graphic titles, and overt period references. The historical portrait drawn by the film in its opening minutes depicts a society moving along parallel pathways in a homogeneous time, punctuated by clear-cut historical events. The recreation of the assassination that occurs several minutes into the film furthers the impression of temporal simultaneity, as the time of day is foregrounded by numerous, almost obsessive cutaways to the clock overlooking Dealey Plaza. Further, when Jim Garrison (the New Orleans District Attorney whose investigation into the assassination serves as the basis of the film) is first introduced, directly after the gunshots, the time of the event is specified orally and underlined visually by rapid point of view cuts from Garrison's perspective to an antique clock. Throughout the opening sequences, then, the dominant temporal form is precisely that of simultaneity and parallelism. The film creates a snapshot of the nation at the moment of the assassination, forging a picture of a national community beset by tragedy, linked, as with the newspaper of the realist era, by the ubiquitous television broadcasts detailing the news of the assassination, the arrest of Oswald, and the swearing-in of Johnson.

This sense of simultaneity and parallelism, the impression the film creates of a community drawn together by a singular, punctual event, begins to dissolve as the investigation into the assassination proceeds. As the past is opened up through a series of characternarrations, the time scheme of the film becomes increasingly complex. For example, in the sequence that summarizes the various mysteries surrounding Oswald, several different layers of time are folded together. First, the scene begins in a reassuring, communal fashion, as Garrison and his staff gather in a favorite restaurant to discuss what they have found so far. A sense of solid, social reality dominates the opening of the sequence, as the maitre $d^{\prime}$ anticipates Garrison's request for a drink, which has already been poured for him, and as various well-wishers exchange greetings. Then, as the Assistant D.A. on Garrison's staff discusses the oddities of Oswald's character, a summary of his life, consisting of black and white still photos, black and white film footage, 
and color "home movie" footage appears as illustration. Periodically, however, another set of images is inserted: color footage of a mysterious hand fabricating the photo of Oswald with a rifle that will appear on the cover of Life magazine, an image that will seal Oswald's guilt in the eyes of the public.

In addition to mixing images that are manipulated or highly ambiguous with images that seem stable and thus imply facticity, the film constructs time here in a way that undermines any sense of its linearity, causality, or embeddedness in social reality. By interrupting the flashback chronicle of Oswald's life with scenes that detail the construction of a composite photograph of Oswald, the film stages the narrative of Oswald's life as a construct detached from the realm of everyday reality and from the solid sense of social space insistently presented at the beginning of the scene. Social reality is abstracted and defamiliarized, as the submerged past that begins to surface here will lead Garrison to say, at the close of the sequence, "(w)e're through the looking glass here. Black is white. White is black."

This is a pattern that will be followed throughout. The characternarrations and subjective flashbacks defamiliarize social reality by narrating the past as a site of contradictory, mundane, and abstracted details, overarched by an almost biblical sense of prefiguration and fulfillment. As Garrison reads the testimony of the train yard manager, Lee Bowers, for example-a witness who spotted suspicious activities taking place on the grassy knoll-the film provides a series of images, attended by Bowers's verbal description, that are specified exactly according to time, place and perspective. At the close of this narration, however, the film suddenly introduces a still photograph of the same man now dead, covered in blood and slumped over the wheel of a car. Only much later in the film will the suspicious circumstances of his death be revealed. Here, the film uses a technique of temporality similar, although not identical, to the Oswald fabrication scene described above: it telescopes time by inserting an achronic, undated, almost unreadable image, an image abstracted from any temporal or spatial connection 
with the rest of the sequence, into a series of images whose chronology is precisely specified. The mundane and the portentous, the particular and the prophetic (a textual motif underlined in the two Cassandra figures who inaugurate the film, Eisenhower and Rose Charmaine, the beaten woman who warns her doctors of the impending assassination) are placed in direct proximity in a way that transforms the past into something other than a horizontal cause and effect chain. The time scheme that dominates the film is one of anticipation within retroversion: flashbacks that also convey an instantaneous, but undatable, image of the future. ${ }^{10}$

Seen as a reflection of discontinuity and disorder in the national narrative, the temporal structure of $J F K$ departs radically from the sense of continuity that traditionally defines the national past, and from the parallelism and simultaneity binding together, in Anderson's view, the community of the modern nation. The temporal collage the film sets up communicates instead the message that the national narrative has come unraveled, that the shots in Dealey Plaza have produced a caesura in the narrative of nation akin to the blackening of the screen that occurs in the film directly after the assassination. Many of the character-narrations, moreover, come from socially marginal people whose testimony would not be seen as credible in a court of law: David Ferrie (a shadowy member of several extreme right-wing groups), Willie O'Keefe (a convicted homosexual prostitute), and the stripper from Jack Ruby's bar, for example, provide vivid and extensive character narrations, which, we are told, will carry very little weight in a legal proceeding. However, by looking to the marginalized and excluded as a source of authenticity and truth, the film implies that a split between the public sphere and the sphere of "the people" has further eroded the concept of nation as "imagined community."

If, as Timothy Brennan says, the nation is an imaginary construct that depends for its existence on an apparatus of cultural fictions, then the disjunctive, fragmentary form of JFK suggests the shattering of social identity. ${ }^{11}$ It encodes stylistic characteristics such as fragmentation, 
rupture, repetition, and the atomistic scattering of details, as a sign of social morcellation, a mark of the falling apart of a once unitary nation. The message conveyed by the film's style thus intersects in complex ways with the positive argument, made by Hayden White, that modernist and postmodernist forms may provide the most effective methods for rendering the events of the recent past. While the film vividly illustrates the thesis White elaborates-that historical reality far exceeds the capacity of any realist form to comprehend it-it nonetheless holds onto the very ideal of a coherent narrative of nation that its own formal structure seems to repudiate.

For White, the chief value of modernist techniques for representing the traumatic historical events of the twentieth century resides in the sense of doubt and uncertainty toward historical knowledge that a modernist approach to the past permits. Rather than assuming an illusory intellectual mastery over the event, a modernist style of historiography finds that the meaning of the past is contestable, because the questions we ask of the event cannot be answered with any semblance of mastery or totality. Historical reality itself has been transformed in the twentieth century, he argues, by the occurrence of events of such a compound nature and magnitude that any objective account or rational explanation based solely on "the facts" can only be illusory, implying mastery over events and contexts that escape explanation. The effort to come to grips with the "modernist" event can only take place in an atmosphere of historiographic doubt.

While such a description clearly corresponds to JFK, with its mood of epistemological skepticism and lack of resolution, the film on the whole places a different kind of pressure on the question of modernism and historical representation. In terms of offering the cinematic equivalent of a sophisticated historiographic analysis, JFK is exemplary: it represents the event cubistically, from competing perspectives; it mixes film idioms, genres, and period styles (documentary, Soviet-style montage, Hollywood naturalism, domestic melodrama, to name a few) in order to represent the variety of overlapping contexts in which the 
event occurs; it foregrounds the artificial and provisional nature of any reconstruction of reality by refusing to predicate any single version of events. Nevertheless, in its overall concern for the relation between the past and an ongoing sense of national identity, the film seems to be split between its modernist form and its desire to reconstitute or recover a seamless national text. Although it uses the full panoply of modernist devices, it implies that a certain sense of history is part of the social imaginary, and that historical ambiguity raises deeply disturbing questions about identity.

Certainly JFK questions history both as a mode of knowledge and as a means of understanding the present. However, by focusing obsessively on a historical event, it also affirms a desperate need for history as the foundation of national identity. It has been said that " $t]$ he interrogation of history is a stage in the search for identity."12 Above all, JFK demonstrates the problematic nature of history in relation to identity, exposing the contradictory faces of a historical narrative that has ceased to function as an expression of the "imagined community."

The images of history evoked by JFK can be described in terms of two competing paradigms. In the first instance, as a result of its obsession, $J F K$ appears to represent a traditional view that a unified and fixed historical reality exists, and could be recovered, were it not obscured by willfully deceptive stories and by the inaccessibility of the crucial facts. Seen in this way, the film sets itself the task of imposing a metanarrative to unify the disparate stories, rumors and contexts of the Kennedy assassination into a coherent frame. At other points, however, and closely similar to White's concept of the "derealization" of the event in the twentieth century, the film seems to represent history as an "epistemic murk," an unstable discourse of fact and fiction, truth and illusion that discloses only the scattered remains of contexts, motives, beliefs, and regimes of credibility. ${ }^{13}$ From this perspective, the film's project might be described as an attempt to write a history that represents the incoherence, the contradictions, and the inconsistencies that characterize the historical text, exemplifying what we might call, 
with Homi Bhabha, the "dissolution of history as fragmentary composition; the decomposition of narrative voice."14 The film's insistence on explaining the historical event, and thereby recovering a sense of the unisonance of the nation is thus contradicted by its violent polyphony, its filtering of the national history through the epistemic murk of rumor, fact and illusion, conveyed through the complex temporality of the jump cut, the fast forward, the freeze frame, and the splitting of sound from image in which the past escapes any possibility of realignment in "homogeneous, empty time."

\section{The imagined community as lost object}

JFK oscillates between these competing paradigms, which are represented, more or less explicitly, in a series of character-narrations. In place of social unisonance, the film provides a series of readings of the assassination, drawn from a wide range of social types. From the almost freakishly marginal David Ferrie to the seemingly informed speculations of " $X$ ", these readings exhibit common characteristics as well as telling differences: they adhere to the same code of explanation, but make different appeals to belief. The confessional nature of Ferrie's account, the anguish and fear that permeates his monologue, conveys a strong sense of truth, underscored by the long-take camera work that seems to wish to offer itself as the equivalent of a visual polygraph test. By contrast, " $X$ " offers the authority of an "inside view," and provides a sense of dispassionate analysis in which logic and history provide an explanatory framework. Juxtaposed in the film in a way that invites comparison, the narrations of Ferrie and of " $X$ " exhibit a striking lack of unisonance at the level of the signifier.

Ferrie's narration, for example, stands out for the simplicity of its scenic construction: in a film characterized by virtuoso editing and stylistic "thickness," this scene is rendered in a straightforward presentation: there are no cutaways, inserts, or dramatized illustrations attending his description. Rather than establishing a unifying frame 
for the murder, however, a metanarrative that would resolve the incompatibilities of different texts and contexts, Ferrie offers a reading of the event that is polysemic: "It's a mystery, inside a riddle, wrapped in an enigma." He concludes by stressing the incomprehensibility of the event, its vastness and obscurity, a plot in which "everyone is always flipping sides," and in which the machinations of the Cubans, the CIA, and the Mob are described as "fun and games. It's all fun and games."

" $\mathrm{X}^{\prime \prime}$ "s narration, on the other hand, charts a different route into the social imaginary. Continuously framed with the monuments of Washington D.C. behind him, " $X$ " speaks of a plot that centers on the control, suppression, and manufacture of information. Cover stories, secret documents, conversations "in the wind" delineate a plot that has been rationally constructed from start to finish, and which could, it appears, be uncovered with sufficient access to "the facts." " $X$ "'s narration, however, is replete with all the techniques that have garnered JFK such a notorious reputation for dissembling: it is filled with imaginary reenactments and recontextualized documentary images that dramatize a far-flung conspiracy emanating from the highest reaches of power. " $X$ ", unlike Ferrie, concludes by telling Garrison that he can and must discover the truth, that his quest is "historical."

Drastically dissimilar appeals to belief are made in these readings: in one case, a straightforward scenic rendering of the character's version of events; in the other, a highly edited aggregation of existing footage, staged reenactments, and rumor made photographically concrete. In juxtaposing these two stories, both consisting of tenuous threads of information, the film exposes a cultural landscape in which different kinds of knowledge, and different types of visual and verbal evidence abound. The different rhetorical strategies characterizing these two narrations of the plot to murder Kennedy, however, come together in a set of common dichotomies: both the testimony from "below" and the testimony from "above" shuttle between explanations based on personal acts of revenge versus collective political acts, between crime 


\section{Robert Burgoyne}

and subversion, between fanaticism and economic calculation, between inside agents and outside agitators.

Underlying the discourse about Kennedy's assasination, however, is the more elusive and oblique subject of the national narrative. In these two dialogues, different rhetorics of national identity, or more precisely, different metaphors and myths of the nation are placed in uneasy proximity. Ferrie uncovers one such myth in his "confession" that all he wanted was to become a Catholic priest, to live in a monastery, to pray to God. One of Anderson's central theses concerning national identity is that "the dawn of nationalism at the end of the eighteenth century coincide[d] with the dusk of religious modes of thought," and that nationalism essentially extended and modernized "religious imaginings," taking on religion's concern with death, continuity, community, and the desire for origins. ${ }^{15}$ For Ferrie, the centrality and communalism of the Church, especially that of the monastic life, stands as an example of collectivity only poorly replicated by the criminal and state-sponsored institutions that have replaced it. Ferrie seems to occupy in a complex way the position of the exile, nationalism's opposite. Referring to Oswald as a "wannabe, nobody really liked him," Ferrie brings to the surface of the text the desire for affiliation, for community, for the univocity of assent. The figure of the exile, seen here in the person of Ferrie as a type hovering around the periphery of the national community, is however displaced, in a paradoxical fashion, into the center of the film's portrait of national life, extending ultimately to the figure of Garrison, who will, like Ferrie, be metaphorically "defrocked," and banished, at least temporarily, from the national community-a point made apparent in the slanted media coverage of Garrison's case against Clay Shaw. Moreover, Garrison's identification with Ferrie is figured directly in the subsequent scene at Ferrie's apartment, in which he looks into the mirror and imagines the circumstances of Ferrie's death. The dichotomy the film sets up between exile and the imagined community illuminates its narrative address: the film posits its viewer as a charter member of the community of nation yet simultaneously 
alienated from it, both insider and outsider, winner and loser, part of the whole yet driven to reject the premises upon which the national community has lately been established.

A very different myth of the nation, and a very different sense of cultural identification permeates the dialogue of " $X$ ". Here, the assassination of Kennedy is placed in a historical frame that encompasses not only the national narrative, but the principal symbols of national identity. Beginning at the Lincoln Memorial, and ending at the eternal flame marking Kennedy's tomb, the sequence details a secret history, a national past that has uncannily woven itself into the communal text. ${ }^{16}$ " $X$ " narrates a history consisting of covert operations in Italy, Tibet, Vietnam, Cuba, that brutally extended and consolidated the reach of American power in the fifties and early sixties. The murder of Kennedy, and the national narrative in general, are described by " $\mathrm{X}$ " in terms of a universal imperial pattern: Caesar, the Crucifixion, the killing of kings, are set out by " $\mathrm{X}$ " as the salient intertextual references for the U.S. narrative of nation.

Counterposed to this clandestine history of the national security state, however, is the implied narrative of national life represented by the monuments to Lincoln and Kennedy, who, the film suggests, are linked in a different chain of affiliation, connected to a different narrative of nation. This narrative of national life is referenced metonymically in the shots of two black children playing on the grassy embankment near Garrison and " $X$ ", and by the black father and son who are seen paying their respects at Kennedy's tomb at the end of the scene. ${ }^{17}$ Blackness in JFK functions almost like a motif, the visible signs of an idealized national narrative characterized by racial and social progress, a narrative capable of binding the whole "national community" together. " $X$ "'s version of the narrative of nation- "The organizing principle of any society is for war. The authority of a state over its people resides in its war powers"-appears to be contradicted by the mise en scene, which evokes a national mythology and a historical life of "the people" that appears to be distinct from the martial 


\section{Robert Burgoyne}

authority wielded by the state. The mise en scene of this sequence illustrates a point made by Bhabha: "The living principle of the people as that continual process by which the national life is redeemed ... [t]he scraps, rags, and patches of daily life must be repeatedly turned into the signs of a national culture."18

Between these different representations of the national past and the national culture-one narrated, the other expressed through mise en scene-a major fissure exists. The "imagined community" portrayed in the film is clearly not fixed, visible, or unified horizontally, but is instead split into several separate and distinct nations: those "in the loop," and those who occupy the position of exile; those who are "faceless," and those who are marked by history. Split and divided, the idea of the nation becomes a kind of lost object in JFK, a unisonance once identified with patriotism and home-signified with exceptional nostalgic power in the lengthy montage scene that opens the filmnow identified with loss and silence.

The imagined community as lost object-the modernist and postmodernist narrative techniques of the film express a sense of the splitting and division of a society, and of the loss of the idealized symbols of national identity. If the development of a coherent narrative mode is essential for achieving a sense of history and of cultural identity, as Anderson and others have argued, the film's anti-narrative techniques would appear to signify identity's dissolution. If the realist novel is understood to serve a "nation-building function, equivalent to the institution of law," JFK would appear to display the divisions of culture, history and symbolism that, the film implies, make our present sense of national identity so dissonant. ${ }^{19}$

On the other hand, the film's radically contestatory interpretation of the past can also be seen as a form of popular counter-memory, bringing forms of popular cultural expression directly into the center of its narrative art. Bypassing the narrative forms of official culture, the film fuses vernacular idioms such as docudrama, grainy, tabloid-style still photographs, television images, and home movies, to create a 
carnivalesque style of narrative texture replete with examples of "bad taste." The cultural and social landscape of late twentieth century America is embedded in the film's montage technique, through which, as one writer says, "different cultural worlds converge: a convergence of differences without uniformity." ${ }^{20}$

The nostalgic desire that permeates the film for a unified national culture, a culture of unisonance, a single national voice, is thus set against its modernist, montagist form, which draws on the multiple popular idioms of contemporary life. Cutting across the different social divisions and narratives of nation in the film, however, is the memory of violence, the memory of discontinuity emblematically figured in the death of Kennedy. In foregrounding the memory of violence, the film resists the reductiveness of a single, official history, and defends the role and power of differentiated memories. Perhaps $J F K^{\prime}$ s greatest strength is its use of the disjunctive style of the contemporary media as an act of cultural resistance, and to fold that message of cultural resistance into an appeal to national identity in a way that recognizes the media as a terrain, analogous to the role of the novel and the newspaper in the past. But this strength might also be seen as the film's greatest weakness, for in the end this message returns us to the dominant narrative of nation and assimilates to national identity all other possibilities of community and solidarity. ${ }^{21}$

\section{Notes}

1 This article has been published in The Persistence of History (Cinema, Television and the Modern Events). Vivian Sobchack, ed. (New York: Routledge, 1995).

2 JFK: The Book of the Film (Applause Books, New York, 1992) contains an extraordinary collection of reviews, commentaries, editorials, and responses comprising several hundred pages, as well as Oliver Stone's and Zachary Sklar's research notes for the film. In addition, Cineaste (vol. XIX, no. 1) has published a special issue on JFK, and American Historical Review (April, 1992) includes a substantial special section on the film. Media Spectacles (eds. Marjorie Garber, 


\section{Robert Burgoyne}

Jann Matlock, and Rebecca Walkowitz, New York: Routledge, 1993) contains several articles that deal with the controversy and debate surrounding JFK.

3 Hayden White provides a particularly sophisticated treatment of these issues in relation to JFK in "The Fact of Modernism: The Fading of the Historical Event," in Vivian Sobchack, ed., The Persistence of History (New York: Routledge, 1995).

4 Benedict Anderson introduces the term "unisonance" in connection with the singing of the national anthem, and the impression of social parallelism and simultaneity it fosters. See Imagined Communities (London: Verso, 1991): 145.

5 The relation between nationalism and narrative form has been addressed by a number of writers. See, for example, Homi K. Bhabha, "DisseminNation: time, narrative, and the margins of the modern nation"; and Timothy Brennan, "The national longing for form" in Bhabha, ed. Nation and Narration (London: Routledge, 1990); William Rowe and Vivian Schelling, Memory and Modernity (London: Verso, 1991); Partha Chatterjee, Nationalist Thought and the Colonial World (Minneapolis: University of Minnesota Press, 1993); and Benedict Anderson, Imagined Communities (London: Verso, 1991).

6 Anderson, 26. The phrase "homogeneous, empty time" comes from Walter Benjamin, Illuminations (New York: Schocken Books, 1969): 261.

7 Anderson, 25.

8 Anderson, 25.

9 White, "The Fact of Modernism: The Fading of the Historical Event."

10 The phrase, "anticipation within retroversion" comes from Mieke Bal, Narratology: Introduction to the Theory of Narrative (Toronto: University of Toronto Press, 1985): 67.

11 Timothy Brennan, "The national longing for form," in Bhabha, ed. Nation and Narration: 49.

12 Renata Wasserman, "Mario Vargas Llosa, Euclides da Cunha, and the Strategy of Intertextuality." PMLA May, 1993: 464.

13 See Ann Laura Stoller, "In Cold Blood: Hierarchies of Credibility and the Politics of Colonial Narratives." Representatives 37, Winter 1992. The phrase, "epistemic 
murk," comes from Michael Taussig, "Culture of Terror, Space of Death: Roger Casement's Putumayo Report and the Explanation of Torture." Comparative Studies in Society and History 26, no. 3 (July, 1984).

14 Homi K. Bhabha, "A Question of Survival: Nations and Psychic States," in Psychoanalysis and Cultural Theory: Thresholds, ed. by James Donald (London: Macmillan, 1991): 98. Bhabha here explores the limits of Anderson's concept of the "unisonance" of the imagined community, drawing on competing models of national consciousness as defined by Edward Said and Frantz Fanon.

15 Anderson, 11. See also Brennan, 50.

16 The iconography of D.C. monuments has been utilized in other film texts in relation to conspiracy in ways that contrast with JFK. In Mr. Smith Goes To Washington, for example, the montage elicits a sense of democracy as transparent; in All The President's Men, by contrast, the official spaces of Washington are represented as signs that must be deciphered for their underlying, conspiratorial connections. But where All The President's Men presents conspiracy as a temporary aberration, which can be purged through the apparatus of "the system" itself, JFK narrates a secret history that "derealizes" the dominant historical narrative.

17 In the script of the film, this scene is handled differently. Rather than a black man and his young son at Kennedy's tomb, the script has Garrison flashing back to documentary images of Dachau, with piles of bodies being bulldozed into a ditch. In the logic of the film, this change underlines the message of the importance of national community, associated with the images of Lincoln and Kennedy. It asserts, under the banner of the national, a sense of black and white having a common story and sharing the same fate.

18 Homi K. Bhabha, "DissemiNation: time, narrative and the margins of the modern nation," in Nation and Narration: 297.

19 William Rowe and Vivian Schelling, Memory and Modernity(London:Verso, 1991): 204.

20 Rowe and Schelling, 213.

21 See Dipesh Chakrabarty, "Postcoloniality and the Artifice of History: Who Speaks for 'Indian' Pasts?" Representations 37, Winter 1992. The concluding paragraphs of this article express well the dominance of national narratives over other, possible narratives of social connection, and stress the role of historical writing in furthering this condition. 